\title{
XLVII. Flexure of long pillars under their own weight
}

\section{Maurice F. FitzGerald}

To cite this article: Maurice F. FitzGerald (1892) XLVII. Flexure of long pillars under their own weight, Philosophical Magazine Series 5, 33:204, 428-431, DOI: 10.1080/14786449208620279

To link to this article: http://dx.doi.org/10.1080/14786449208620279

曲 Published online: 08 May 2009.

Submit your article to this journal $\pi$

Џll Article views: 2

Q View related articles $\sqsubset$ 


\section{[ 428 ]}

XLVII. Flexure of long Pillars under their own Weight. By Maurice F. FitzGerald *.

T $\mathrm{HE}$ origin is taken at the upper end of the neutral axis, abscissæ being reckoned positive vertically downwards, and ordinates horizontal. The flexure is supposed small, and assumed to lie in a vertical plane. The symbols employed are as follows:-

$\mathrm{H}=$ total height of pillar ;

$h=$ height below top of any point in it ;

$\mathrm{S}=$ total shear on a section normal to neutral axis ;

$\mathrm{M}=$ bending -moment ;

$w=$ weight of pillar per unit of length ;

$\mathrm{E}$ and I, as usual, stand for the coefficient of flexural elas ticity, and moment of inertia of cross section, respectively.

Taking a plane, A B (fig. 1), normal to the neutral axis, the shear on this plane is the component along it of the weight of the upper part of the pillar (whose top is supposed free); for small bending we have therefore

$$
\mathrm{S}=w h \frac{d y}{d h} \text { nearly. }
$$

Fig. 1.

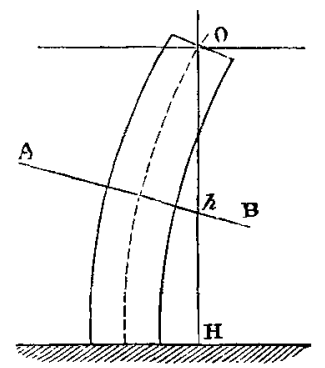

By well-known theorems, $\frac{d \mathrm{M}}{d h}=\mathrm{S}$ and $\mathrm{M}=-\mathrm{EI} \frac{d^{2} y}{d h^{2}}$, which give by substitution,

$$
\mathrm{EI} \frac{d^{3} y}{d h^{3}}=-w h \frac{d y}{d h}
$$

By writing $\frac{h}{\mathrm{H}}=x$ and $m=\frac{w \mathrm{H}^{3}}{\overline{\mathrm{EI}}}$, this takes the form

in which, putting $\frac{d y}{d x}=u$, we get

$$
\frac{d^{3} y}{d x^{3}}=-m x \frac{d y}{d x}
$$

$$
\frac{d^{2} u}{d x^{2}}=-m x u
$$

a differential equation which enters into other questions.

The value of $x\left(=\frac{h}{\mathrm{H}}\right)$ runs from 0 at top to 1 at foot of pillar; $m$ has, except for pieces ot fine wire a few feet in length, or for very unusually tall and large columns, only a small fractional value in practice.

* Communicated by the Physical Society: read February 26, 1892. 
Integrating the equation $\frac{d^{3} y}{d h^{3}}=-m x \frac{d y}{d h}$ in series, we get

where

$$
y=\mathrm{AU}+\mathrm{BV} \text {, }
$$

$\mathrm{U}=x\left\{1-\frac{m x^{3}}{2.3 .4}+\frac{m^{2} x^{3}}{2.3 .5 .6 .7}-\frac{m^{3} x^{9}}{2.3 .5 .6 .8 . y .10}+\ldots\right.$

$\mathrm{V}$ is another series, having $x^{2}$ as a factor, and $\mathrm{A}$ and $\mathrm{B}$ are arbitrary constants.

Calling the first derived function, with respect to $x$, of $\mathrm{U}$, $\mathrm{U}^{\prime}$ and so on, the condition of a pillar free at top, and fixed initially vertically to a rigid base is expressed by

and

$$
\frac{d y}{d x}=\mathrm{AU}^{\prime}+\mathrm{BV}^{\prime}=0 \text { when } x=1 \text {, i. e. at foot, }
$$

$$
\frac{d^{2} y}{d x^{2}}=\mathrm{AU}^{\prime \prime}+\mathrm{BV}^{\prime \prime}=0 \text { when } x=0, i . e . \text { at top, }
$$

since there is no bending-moment at top.

As $\mathrm{V}$ contains $x^{2}$ as a factor, the second of these gives $\mathrm{B}=0$, and the first then requires $U^{\prime}=0$ when $x=1$. It will be found, on inspecting the curves plotted in fig. 2 , that a value

Fig. 2.

$$
\begin{array}{ll}
y=\mathrm{U}_{x=1} & \frac{d^{3} y}{d x^{3}}=-m x \frac{d y}{d x}, \\
u=\mathrm{U}_{x=1}^{\prime} & \frac{d^{2} u}{d x^{2}}=-m x u .
\end{array}
$$

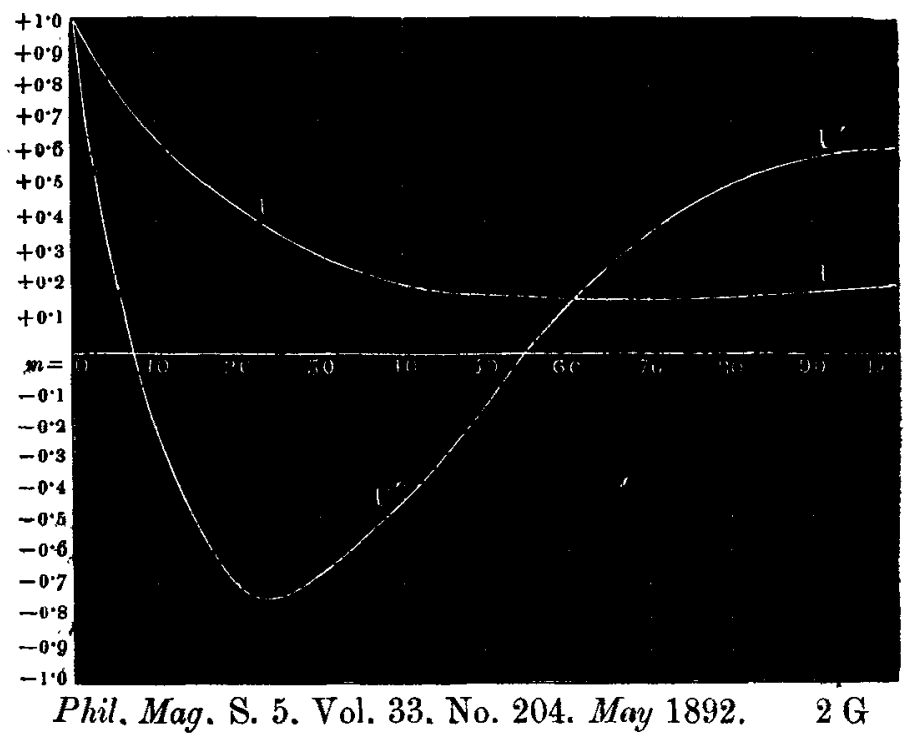


of $m=7.85$ nearly is that required. For dimensions in feet, and for steel in which $\mathrm{E}=$ about 12,000 tons per square inch, this gives, on putting in the numerical values, and putting $\mathrm{L}=$ ratio of length to diameter,

$$
\mathrm{H}(\text { in feet })=\frac{8 \cdot 1 \times 10^{6}}{\mathrm{~L}^{2}} \text { for steel tubes, }
$$

$\mathrm{H}$ being here independent of the thickness, supposed small ; and

$$
\mathrm{H}=\frac{4 \times 10^{6}}{\mathrm{~L}^{2}} \text { for round steel rods, }
$$

as the limiting height of pillar which can stand without bending under its own weight. Thus for $\mathrm{L}=100$, the maximum height is about 800 feet, giving a tube 8 feet diameter. For wires, $L$ may be much greater; for instance, the limit at which bending due to its own weight, of wire originally straight and vertical, size No. 28 B.W.G., must occur is about 1.8 feet.

All columns, in practice, naturally fall far within the limits here given. In connexion, however, with the inherent flexibility of very large masses under their own weight, even when direct crushing is prevented (say by external fluid pressure), it may be remarked that for $\mathrm{L}=4, \mathrm{H}=47$ miles, approximately; so that a solid steel column 12 miles diameter would bend, even if prevented from bulging, if it were 50 miles high.

The only case of interest, besides that of a column fixed at its base and free at the top, above treated, seems to be that of a heavy upright column, held at top and bottom by external bending-moments so that the neutral axis is vertical at both ends, but otherwise free.

In this case, denoting by suffixes the values at each end, we have

$$
\begin{array}{ll}
\mathrm{AU}_{0}^{\prime}+\mathrm{BV}_{0}^{\prime}=0, & \mathrm{AU}_{\mathrm{l}}^{\prime}+\mathrm{BV}_{\mathrm{l}}^{\prime}=0, \\
\mathrm{AU}_{0}^{\prime \prime}+\mathrm{BV}_{0}^{\prime \prime}=\mathrm{M}_{1} \mathrm{H}^{2}, & \mathrm{AU}_{1}^{\prime \prime}+\mathrm{BV}_{1}^{\prime \prime}=\mathrm{M}_{2} \mathrm{H}^{\mathbf{2}} .
\end{array}
$$

$V_{0}^{\prime}$ and $U_{0}^{\prime \prime}$ are both zero identically; $U_{0}^{\prime}=1$, and $V_{0}^{\prime \prime}=2$, which give $A=0 ; 2 B=M_{1} H^{2}$; and, on substitution in the second and last of the above equations, we get

$$
\mathrm{BV}_{1}{ }^{\prime}=0 \text { and } \mathrm{M}_{1} \mathrm{~V}_{1}{ }^{\prime \prime}=2 \mathrm{M}_{2} \text {, }
$$

where, in $V_{1}^{\prime \prime}$, the value of $m$ which makes $V_{1}^{\prime}=0$ is to be inserted. The result shows that there is, in this case, a definite ratio between the external bending-moments.

Precisely similar results, as to producing bending, would take place in a bar accelerated by a force applied at its back 
end, neglecting longitudinal sound-waves; as also to a liquid filament retarded, if it possessed uniform stiffness in virtue of any internal motion.

Belfast, February 1, 1892.

Since the above was in print Prof. A. G. Greenhill, F.R.S., has sent to the writer a paper, published in the Proc. Camb. Phil. Soc. vol. iv. 1881, written by him for Prof. Asa Gray, on the greatest height of poles, masts, and trees, consistent with stability. The differential equation involved is, in Prof. Greenhill's paper, solved by the aid of Bessel's functions, and the investigation is extended to the cases of a solid cane, and a paraboloid of revolution, the general form of the solution for certain other solids of revolution being given. The results for a wire (allowing for a slight difference in the value assumed for E) given by Prof. Greenhill are the same as those above. The function $U^{\prime}$ tabulated in the curve fig. 2 appears, from Prof. Greenhill's paper, to be connected with $J_{n}\left(\kappa x^{m}\right)$ by the relation

Belfast, March 16, 1892.

$$
\mathrm{U}^{\prime}=x^{\frac{1}{3}} \mathrm{~J}_{-\frac{5}{5}}\left(\kappa x^{\frac{3}{3}}\right)
$$

XLVIII. Note on the Change of Heat Conductivity on passing isothermally from Solid to Liquid. By C. Barus.*

TN an earlier paper $\dagger I$ gave an account of the volume 1 expansion and of the change of thermal capacity of thymol, observed quite throngh the temperature interval $\theta=0^{\circ} \mathrm{C}$. to $\theta=50^{\circ}$ (melting-point), both for the solid and the liquid state. I have since considerably extended these observations. If $\rho$ be density and $c$ be specific heat, I found for liquid thymol $\left(0^{\circ}-50^{\circ} \mathrm{C}\right.$ ),

$$
1 / \rho=1 \cdot 0113 /(1-(\cdot 0007600+2 \theta) \theta)
$$

and $c=\cdot 4475(1+\cdot 00238 \theta)$; and for solid thymol $\left(0^{\circ}-50^{\circ} \mathrm{C}.\right)$,

$$
1 / \rho=\cdot 9631 /(1-(\cdot 0002456+2 \theta) \theta) \text {, }
$$

and $c=\cdot 3114(1+\cdot 00302 \theta)$.

With these data in hand I was able to attack the corresponding problem in thermal conductivity. I made use of a somewhat modified form of H. F. Weber's $\ddagger$ method, since it is well adapted for measuring small conductivities and meets other requirements of the present problem. If $\Delta$ be the

* Communicated by the Author.

$+C f$. Proceedings American Acad. xxvi. p. 313 (1802).

I Wied. Ann. x. pp. 103, 304, 47: (1880). 